\title{
Project launched to develop ventilator parts and masks
}

Researchers at the University of East Anglia (UEA) have launched a project to 3D-print ventilator parts, masks and other critical equipment to battle the COVID-19 pandemic.

UEA are working with the tech community to access $3 \mathrm{D}$ printers, as well as people with the necessary skills to work at pace to design and make equipment.

\section{'UEA are working with the} tech community to access 3D printers, as well people with the necessary skills to work at pace to design and make equipment.'

They are also collaborating with healthcare providers to understand their needs and hope to mobilise similar projects at other universities nationally and globally.

The team are looking to collaborate with people with software skills, particularly Solidworks for CAD design, and those trained in 3D scanners and conversion of files to STIL files (printable version). They are also looking for printers - specifically
Fused Deposition Modeling (FMD), that uses thermoplastic filaments, brands Makerbot or similar, and SLA type printers which use liquid resins.

The scope of the project may move into re-purposing or reconfiguring existing ventilators, rapidly developing new ventilators and producing other medical supplies such as PEEP valves and face shields.

Project lead Dr Aram Saeed, from UEA's School of Pharmacy, said: 'It is absolutely vital that universities join forces with healthcare providers and businesses to find creative solutions to fight COVID-19.

'We need shortcuts to speed up the process of designing and developing key ventilator parts, and we hope to connect with other universities and expertise around the globe.

'It's still very early days for this project, but the response so far has been amazing. It is very much a steep learning curve, but we have a fantastic team of researchers and $\mathrm{PhD}$ students working on this, and we will be using our academic networks to help solve the problem.'

To find out more visit: https://www.uea. ac.uk/about/-/ventilators.

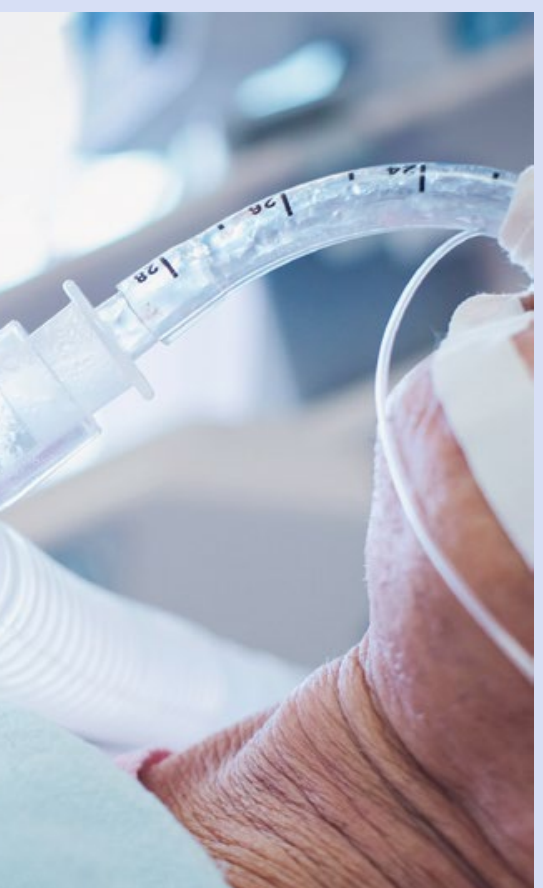

\section{IR35 changes}

\section{postponed}

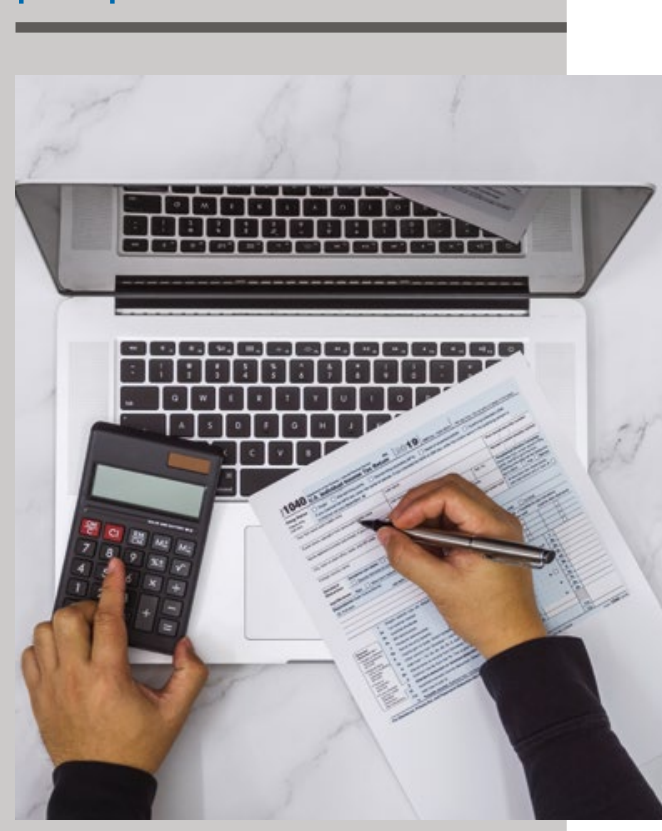

In light of the COVID-19 pandemic, changes to the implementation of the Off-Payroll (IR35) Tax is now due to be reintroduced in April 2021.

The decision was taken following significant pressure from many who warned that the inevitable loss of work due to the virus for contractors deemed 'inside IR35' and effectively forced into 'zero rights employment' would prove catastrophic.

When announcing the decision, Chief Secretary to the Treasury, Steve Barclay MP to the House of Commons, said: 'This is a deferral in response to the ongoing spread of Covid-19 to help businesses and individuals. This is not a cancellation, and the Government remains committed to reintroducing this policy to ensure people working like employees but through their own limited company pay broadly the same amount of tax as those employed directly.

Alan Suggett, Partner at UNW LLP and Media Officer of NASDAL (National Association of Specialist Dental Accountants and Lawyers) commented: 'While postponement is welcome, we know that dentists and dental practices have many more pressing concerns currently in the wake of the Coronavirus outbreak' 